\title{
Religion and Self: Notions from a Cultural Psychological Perspective
}

\author{
Jacob A. Belzen
}

Published online: 25 March 2009

(C) The Author(s) 2009. This article is published with open access at Springerlink.com

\begin{abstract}
After a brief introduction of a cultural psychological perspective, this paper turns to the concept of self. The paper proposes to conceive of that reality to which the concepts of self refer as a narrative, employing especially autobiographies and other ego-documents in empirical exploration. After discussing some psychological theories about "self," the paper points out that they may well be applied in research on personal religiosity.
\end{abstract}

Keywords Cultural psychology $\cdot$ Self $\cdot$ Mental health

\section{Introduction: A cultural psychological perspective}

It is not easy to state in only a few words that which the title of this paper refers. I shall have only the possibility to make some very general statements, hopefully not too sweepingly formulated, and to articulate only a few more precise observations on a couple of theories on a psychological construct sometimes called "the self," but more correctly hinted at by not employing the definite article "the," so referred to by only the term "self" (see below). All of this may sound clumsy, and perhaps it is. The truth is, however, that we are not dealing here with anything that would be conceptually clear: after more than a century of research and theorizing, psychologists still can't tell what that is: self. Nor can they satisfyingly explain what "mental health" is. (And both "religion" and "culture" are not concepts to be defined by psychologists, we have to leave that to other disciplines.) Most concepts in psychology are not clear, and whenever they are clearly formulated, it can usually be pointed out that they fall short of capturing the empirical reality they are aiming at. (Although relevant here, I shall not go into the difficult issue of concepts, and of language in general, constituting reality, cf., e.g., Lakoff and Johnson 1980.) Trying to be faithful to the central topic of our conference, I shall try to come up with some observations that hopefully will prove to be worthwhile to practitioners in the realm of counseling and

\footnotetext{
J. A. Belzen $(\bowtie)$

Psychology, University of Amsterdam, Oude Turfmarkt 147, NL-1012 Amsterdam, The Netherlands e-mail: belzen@hum.uva.nl
} 
psychotherapy, although these observations will, in the realm of psychology, never lead to simple recipes.

One of the reasons that the very object of the science called psychology if it is a science at all is so difficult to conceptualize, is that it is evasive. The psychic realm is fundamentally different from the realm of the natural science, whose object is not easy to conceptualize either, by the way. The psychic realm is not constituted of objects like the ones we handle with our hands in ordinary daily life. A common psychic phenomenon like a dream is not something you can touch or investigate like a piece of wood or like a stone; it is not even an entity like the human body including the human brain. Psychic reality, comprised of phenomena like attention, memory, thought, feeling, desire, anxiety, self concept, etc. and characterized by intentionality, has given rise to a multitude of approaches and of efforts of conceptualization. Great theoreticians among the founding fathers of psychology have come up with radically different models of the human person or of the human mind, of the psyche, or what way ever they preferred to call their object of study. What we do know, however, is that the psychic realm is constituted, regulated and maintained by culture understood in the broadest sense: without culture, no new born baby would survive, without culture, the human being is inconceivable. To culture also belong the varieties of religious and spiritual traditions we witness in past and present. Cultural psychology, therefore, stresses that cultural patterns of acting, thinking and experiencing are created, adopted and promulgated by a number of individuals jointly. Such patterns are supra-individual (social) rather than individual, and they are artefactual rather than natural. Thus, psychological phenomena are cultural insofar as they are social artifacts, i.e., insofar as their content, mode of operation and dynamic relationships are a) socially created and shared by a number of individuals, and b) integrated with other social artifacts (Ratner 2002, p. 9). Conversion, e.g., is a phenomenon found within certain religions, having a different meaning within different subgroups of such religions, being the result of certain patterns of religious practice, in their turn related to certain religious doctrines and rituals (Belzen 1999). In cultural psychology usually the meaning of some form of action (or thought or experience) is central, not the action as such (which could be and in fact often is studied by other social and human sciences too). Culture, also cultural practices, is being conceived of as symbolic: it is considered to do more than merely represent preexisting realities and regulate behavior. Rather, culture is being seen as creating (social) reality, whose existence rests partly on such cultural definitions. With this, cultural psychology recognizes the open and indeterminate relationship between cultural meanings, practices and material forces. It is recognized that not only social institutions (e.g. marriage, school), roles (e.g. bride, student) and artifacts (e.g. wedding ring, lecture notes), but also psychological concepts (e.g. the self, emotion, mind) and epistemological categories (e.g. time) depend, in part, on cultural distinctions embodied in language categories, discourse, and everyday social practices.

\section{Self narratives}

If we turn to just one psychological concept merely understood as an effort to conceptualize something about human psychic functioning to the so-called self, we see these general observations readily illustrated. Self is not a "thing" like other things we encounter in the world, therefore the use of the definitive article "the" is inappropriate to refer to it; what is referred to, in fact, is a dynamic human process, the nature of which is very hard to conceptualize. Self is not a natural entity, no one is born with a self, a sense of self needs to 
develop, and whatever that self is, it varies in different contexts, also in the different contexts that are the different phases of the individual life. How could any psychologist have access to that self? How to do research on this process? How to take self into account in psychotherapy, for instance? We need to realize that self is only given in language, and therefore only accessible through language. It is in the speech, in the talking of the patient, in her words, in her phrasing, in her metaphors, in her use of symbols, that self displays itself. (Mind: I am not saying that self manifests itself in speech only; in many other forms of human acting self may display itself too; but if we want to know what such acting means to both the actor and her fellow human beings, we need to employ language again. For psychologists, therefore, self is only accessible in speech and other linguistic activities or their results.) It is not only in actually talking that self reveals itself. It is only detectible in the narratives that have been kept in the form of answers to open questions in questionnaires, in records of interviews or in all kinds of other linguistic materials psychologists work with in empirical research. Also autobiographies are an example of such material, and as is obvious, they have been employed in even the earliest empirical investigations in the psychology of religion already.

We should be aware of the perspective of any psychological theory, of its specificity. When psychology turns to self narratives like autobiographical texts, it does not do so to examine the situations described in them or to reconstruct particular events or points in time; such research, interesting as it may be, is usually left to historians. Nor does psychology delve into the existent or nonexistent literary qualities of an autobiography, or into the genre of autobiography as such; this is the realm of literary theorists. When psychology avails itself of autobiographical texts, it does so by asking psychological questions and from a psychological perspective. The most important argument for doing this is usually that working with autobiographical texts, in whatever form (they certainly need not be limited to published autobiographies but may include texts written at the explicit request of the researcher, diaries and many other forms of autobiographical data; cf. Bruner 1990, for example), is the most effective way of gathering information for certain kinds of questioning. If the researcher is interested in studying the development of someone's identity, for example, hardly a better method can be devised than to ask the research participant to provide at regular intervals a text that is as subjective and personal as possible. Even when psychologists look at existing autobiographies, published or not, they do so in order to find answers to systematic psychological questions concerning such factors as psycho-social development, parent-child binding and social relationships in general, guilt and shame, experience of sexuality, mental disorder and many others. For the psychologist who is interested in religion, autobiographical texts may provide a great deal of information concerning the development of individual religiosity and the influence that certain forms of religion can have on the development of the personality.

Autobiographies can also serve as an important source of information for research on that which psychologists call "self," since it is in an autobiography that an author presents herself. She presents herself in a certain way, telling us a story about herself and her life. In doing so the author usually draws an ideal picture of herself. Although the story itself need not be ideal in any way (and the author may be reporting it with quite a bit of shame), he paints a picture of himself, which he hopes the listener or reader will accept and endorse. The particular self narrative or autobiography a counselor or therapist needs to interpret may be that, what the patient is telling right now, it may be the story written on request of counselor, it may even be a published autobiography. One can employ several forms of psychology in order to interpret it; in a context of counseling or psychotherapy, it will typically be a form of psychology relevant to issues of mental health. But before going 
shortly into that, let me try to take away any misunderstandings the above may give rise to already. For often the first reaction to idea of the autobiography as presentation of the self, and to the self as a narrative construction, is that of shock. Does this mean that a person's self or identity is "only" a story? Wouldn't it be possible then for someone to tell any manner of story about herself? People tell many different stories throughout their lives, and they also tell different versions to different listeners. If all those stories are what the self, or the selves, of a particular person are, where is the unity of that person? Let's deal briefly with these questions and get a bit more formally theoretical now.

\section{Self as a concept of psychology}

Self is fundamentally characterized, even constituted, by language and story. For the development and functioning of human self-awareness - regarded by many theoreticians, in line with Hegel, as precisely that which distinguishes the human being from the animallanguage is of vital importance. Self-awareness, says Kojève (1947, pp. 163-168), presupposes that the human being, by using the personal pronoun "I," is able to locate himself as distinct from the world of objects and even from himself. So according to Kojève there is an intrinsic connection between self-awareness and language: in fact, there can be no self-awareness without language. The psychoanalyst Lacan (1966) would later speak of the "birth of the subject," referring to the process by which the child enters the symbolic order and in particular learns to handle and to conform to the language he encounters in his subculture. In order to speak about herself, a person must have developed the ability to objectify, which she does thanks to language. So language is a precondition that makes subjectivity possible, and not the other way round. There is not an essential subject who desires to make use of language; rather, the constitution of the subject presupposes language (Haute 1993, pp. 165-167). When the subject, once constituted by language, wants to know something or share something about herself, she must avail herself of language if she is to tell herself or others who she is; she must make an announcement concerning who she has become up to that point. "Up to that point"-for the human being is an historical creature: her life, between birth and death, is a history. That history can be expressed in different places and different ways. It can be imparted in the form of a story. If people are asked to indicate who they are, they will answer with some kind of life history. Indeed, human transience can only be expressed linguistically. To specify this linguistic structure, Ricoeur (1981, pp. 169-172) uses the term "narrativity." Man has a narrative structure by virtue of his historicity: he must relate history, especially his own history (Zwaal 1997, p. 100). This makes the self not only a product of the past but also an interpretation of the past.

In developing her own notion of herself, woman must rely on the stories that are passed on to her and that are absorbed by her, as it were, during socialization. Each story about ourselves is always already embedded in the continuing story of a particular cultural history. The possibilities for self-comprehension that we acquire and develop are themselves always products of a particular historical tradition that makes us its product (Heidegger 1927). Such stories, which inhabit and form our lives and make them possible, are first of all the stories that constitute the background of every notion within a certain culture. They are embodied not only in our views of humankind, the world and life itself but also in art forms and rituals that are shared by all the participants in that particular culture. They are the archetypal stories from every culture, and we run across them in metaphors and expressions, films and plays, but also in functional symbols such as a cross 
or crucifix, the V-for-victory sign, in monuments and in symbols that are associated with commemorations as well as with holidays and festivals (Guignon 1998, p. 569). These are the stories that impart structure to the ordinary, mundane stories we experience and indulge in every day and give them meaning by making available a certain horizon of comprehension. Naturally such archetypal stories differ from culture to culture (and subculture to subculture). The optimistic stories about the redemptive self from the United States (McAdams 2006) are very different from those about sacrifice and suffering that the Russians grow up with, and both are quite distinct from the archetypal stories about ritual suicide such as those making the rounds in Japan. Such fundamental differences can make the life patterns of one culture or subculture seem pointless in the eyes of another (just think of how the forms of Roman Catholic monastic life are perceived by certain Protestants). Second, the impact of stories can be found in the ordinary, everyday way that people communicate with each other. Whenever we engage in an ordinary conversation, we structure our stories according to the storytelling standard that is or is becoming generally accepted within our culture. In doing so, we often use narrative cues that inform the listener as to the kind of story she is about to hear. (An opening sentence such as "Once upon a time" calls for an entirely different kind of comprehension than "What rotten luck I had yesterday.") So we are very far from being able to tell any random story about ourselves (or even to consciously construct such a story); indeed, the ways in which the self can be articulated is subject to strict limitations that usually remain implicit. While language and story make the self possible, they also determine its limits.

\section{Examples of psychological theories}

In narrative psychology, such as that introduced by Sarbin and others (Sarbin 1986a, 1986b, 1993; Sarbin and Kitsuse 1994; Sarbin and Scheibe 1983), these notions are expanded to cover broader parts of psychic functioning than self alone. In one programmatic text, "The narrative as a root metaphor for psychology," Sarbin (1986a) introduces the "narratory principle": "human beings think, perceive, imagine and make moral choices according to narrative structures" (p. 8). He sees emotions, for example, as inextricable from their social context. In his analysis he uses the image of a scene with many individuals in which the action of one participant functions as the focus for the following actions that are carried out by the person himself as well as by the other participants. (So emotions should never be studied as events that happen within a single individual.) According to narrative psychologists, however, it is not only emotions that are led by narrative plots; actions are, too. In listening to and telling stories there is an involvement in the actors and their adventures. Action is not only present in the story, however; it also follows from the story. The so-called Don Quixote principle states that people act in order to extend the plot of a particular story, especially when they imagine themselves to be the protagonist of that story. The Don Quixote principle refers to the practice of shaping one's identity by emulating stories. The central idea is that the narratives with which the cultural participants have become acquainted go on to determine their actions: they provide the characters, ideas, settings, instruments and procedures that individuals and groups can use to give shape to their own activities.

The narrative approach directs attention to the interface between individual and collective functioning, and is therefore particularly relevant for cultural psychology, also in its application to religion. Narrative psychology is an attempt to understand human functioning as culturally located: no matter what emotion or form of activity a person is about to display, it is seen as dependent on the stories, the plots and the roles from the 
culture or subculture in which the person grew up and in which she now happens to be functioning. Because there are always others present in the current situation, real or imagined, every act is an interactive occurrence, always directed at one or more others. And at different times and places the person will present versions of himself that deviate from each other to a greater or lesser extent. (Thus a life companion will be shown a self that is different and probably more private than a colleague, etc.) But no matter what stories are told about the self, they will all follow existing plots. For this reason, Hermans and Kempen (1993) - by analogy with Bakhtin (1929) and using the terminology of James (1890) and Mead (1934) - present the self as a polyphonic novel: a person standing in a multiplicity of worlds in which a story about a "me" with an accompanying "I" can and must be told, over and over again. Those stories can be relatively independent of each other (and sometimes even contrary to each other) and the I's of the different stories can even communicate with each other within the same self. There are different worlds with different stories told by different I's, but there is no overarching I that organises and/or coordinates the different me's. So the self is not one and undivided, not always and everywhere the same; it is plural and context-dependent, a decentralised multiplicity of I positions that function in dialogue like relatively independent authors. That is: they tell each other stories about their respective me's as actors.

According to an even older tenet of literary theory, every text - and therefore also the articulation of a self at a particular time and place - is a result of relations between texts, a product of intertextuality, a membrane into which elements are woven that had already been produced elsewhere in discontinuous form (cf. Sprinker 1980). So the dialogicity of the self presupposes much more than a conversation with whomever is present in the here and now, whether through direct eye contact or not. The articulation of the self, as it emerges at a certain time and place, does not sound like just one single voice; in such an articulation the resonances of other voices can be heard: the voices of the parents and significant others as well as the voices of collectives such as a social class, a professional group or a religious tradition. It is especially the social voices, such as those alluded to by Bakhtin (1929), that have influence on what a person says, that determine what she can say in the first place, usually without being conscious of the fact. There are many personal, unique voices in the self, but there are also a numberperhaps a far greater number - of collective voices. So to repeat: people cannot tell any random story they choose in order to articulate who they are. The stories they tell, the meanings they construct and the sense they impart are dependent on the interplay of various voices.

Still other forms of psychology that are quite different from the possibly obvious narrative psychology offer other points of view that might be relevant in a study of a person's own life story. Ideally, one should try to combine quite diverse forms of psychology to interpret a particular self narrative. Psychology at large is a very heterogeneous enterprise, with many differing approaches, that sometimes even seem to contradict one another. In my opinion, this is no problem at all: reality, also the life of one particular individual, will always be richer than what any form of scholarship will have to say about it. To understand another person, psychologists will, by necessity, have to employ very diverse forms of insights and research techniques.

\section{The psychologies of the self: A plurality applicable to the study of religiosity}

Obviously, all of this also counts when one is interested in religion or religiosity, either as a psychologist setting out to do research or as a counselor or psychotherapist in a clinical situation, working with actual persons, with "living human documents," as Boisen coined a phrase so nicely. We might wonder whether and to what extent someone's story could 
provide insight into a possible relationship between religion and psychic functioning. With this question in mind, we take up one of the oldest research traditions in the psychology of religion. The more specific question concerning the relationship between religion and mental health has always been a prominent one in psychology of religion, and not only because of its presumed social relevance. Even the founding fathers of the field of psychology dealt with religion in terms of "healthy mindedness," "the sick soul," and "the divided self" (James 1902/2002) and made methodical comparisons between religious rituals and obsessional neurosis (Freud 1907). The animosity between psychologists and representatives of religious organizations has sometimes been bitter, but after more than a century of research and formulation of theories a consensus seems to have been arrived at: it is almost impossible to make general statements. Religion may be 1) an expression of mental disorder, 2) a socializing and oppressive force, helping people cope with their life stresses and mental aberrations, 3) a protective agent for some mentally disturbed persons, 4) a therapy, 5) a hazard (Spilka et al. 2003). The relationship between religion and mental health can thus be structured in a variety of ways, and in any individual case it is good to consider what type of connection is at work. One interesting example is a clinical case I have been working on myself (Belzen 2004): the case of an autobiography in which the "I" person tells how she was cured of a serious depression thanks to "religion" (a term that is far too broad and requires a more detailed explanation) but who was turned away by the very religious communities she wished to serve. The reasons for this rejection are certainly relevant but are not fundamental for the psychologist: her primary interest will be what motivated the author to write an autobiography and what psychic functions were involved, and among her questions will be those concerning the connection between religiosity and psychic functioning. I shall not go into this case any further here, however. In order to avoid making the impression of being one-sided, or to have left the domain of traditional psychology, I want to remind again of the many, vary different types of psychological theory, also about self.

Next to these contextualizing perspectives, there are a great number of psychological approaches that have their focus on the development of the person within a certain context, on the history of individual subjectivity. So-called psychodynamic theories typically belong to these approaches. It is another set of questions, about the same person, that may be asked utilizing such theories. To illuminate the difference between these approaches, let me give an obvious and probably recognizable example, drawing on the case I have been studying: A patient may paint herself as someone "special," as someone who, after a difficult childhood, managed by dint of hard work to become a successful businesswoman, and who, while still quite young, retired from her business to live from her private means like a woman of rank, moving in the better circles. She may paint herself as someone who, after undergoing the requisite hardships in life, is blessed by God, someone who has special experiences with God and has been chosen by him to be his instrument in this world. She may present herself as someone who has a story to tell, a story that is so worthwhile that it should be heard by as many people as possible because they stand to profit from it. As psychologists, we may rightly ask ourselves what this tone means, what it refers to or what caused it. The identity presented in this way is - as with every presentation of the self-a desired identity, and it exhibits all the standard problems that are part of the concept of identity. Identity as a narrative given is a text that obscures its own meaning, a meaning of longings that the author does not and usually cannot recognize (Ricoeur 1970). So psychoanalysts such as Lacan point to the problematic status of the identity. According to Lacan, identity is a construct realized in the realm of reality that he called the "imaginary" and is followed by doubt and by suspicions concerning one's own understanding of self, 
while at the same time it is also the desperate antidote against internal fragmentation, conflictual longing and threatening chaos (Rosenberg et al. 1992, pp. 41-42). So one may well inquire whether there may have been inner needs in someone's life that cause her to talk, and perhaps to write, as she does (or did).

Psychoanalytical perspectives can be worthwhile when used as heuristics and one could try to use some of them as a complement to insights gained from working with approaches like narrative psychology discussed so far. One particular psychoanalytic theory also goes by the name of "self psychology," and was developed by Heinz Kohut. (Of course, utilizing the same word "self" Kohut does not refer to exactly the same entity as e.g. James, Mead or Sarbin.) According to Kohut, self comes into being through the sufficient, empathic mirroring of the child by the mother (or another primary caregiver; for the sake of convenience, however, we will continue to speak of the mother). The process by which the neonate becomes conscious of the separation from the mother is by its very nature difficult: the child must begin to realize that an outside world exists which is not subject to his wishes, and that the mother is not always available to him. For the neonate, who must rely on others for his survival, there is something life threatening about this situation: if no one were to respond to his need for care, he would die. The child responds to this frustrating perception with the development of a certain hallucinatory desire, by which he tries to preserve the unity and completeness that have been lost. On the one hand he develops a grandiose image of himself (based on what has now become an aphorism: "I am perfect"), and on the other hand he forms the image of an almighty other, an idealised parent imago who is assigned to serve as guarantor of care and protection ("you are perfect, but I am part of you," Kohut 1971, p. 27). (According to Kohut this takes place among children between the ages of about 8 months and 3 years.) If the parent relates to the child with empathy, she thereby fulfils two functions that are necessary for the child: on the one hand by accepting the child's grandiose image of itself, by admiring the child and making him feel that he is indeed very special, and on the other hand by making herself available as an object of admiration. (In this way parents fulfill the so-called self-object function: they function as the first self-objects for the child.) What matters is not so much what the parents do as how they are: it is the quality of the interaction with the parents that is internalized by the child. If the parents fall short in this regard, the child will not be able to develop a normal, healthy "sense of self." He will continue to have doubts about himself and his self-worth, precisely because he was not mirrored, or not enough. He will have to go through life without a sufficiently crystallized sense of being "allowed to exist," of being "good enough," a feeling he can fall back on when he meets with adversity in life and from which he can continue to derive self-worth even in the face of failure. It is inevitable, however, that parents will not always respond fully to the needs of the child. According to Kohut that is neither necessary nor even desirable. By means of all sorts of small but non-traumatic frustrations, what he calls "transmuting internalization" can take place by which both necessary functions are gradually disconnected from the parents and absorbed into the self. The grandiose image of the self thereby becomes more realistic: from exhibitionistic narcissism it becomes the "fuel for our ego-syntonic ambitions and purposes, for the enjoyment of our activities, and for important aspects of our self-esteem" (Kohut 1971, pp. 27-28). In the same way, the idealized parent imago is transformed into ideals to be pursued. The "grandiose self," the image of the self as grandiose, ${ }^{1}$ is the first to become part of the nuclear self. This takes place between about the second and fourth years (Kohut

\footnotetext{
${ }^{1}$ This is an example of Kohut's often inconsistent use of language: he uses the same word to refer to the image of the self as grandiose ("self") as to the self of which this image is a part.
} 
1977, p. 178). This self is mainly derived from the relationship with the mother. The "idealized parent imago" forms between the fourth and sixth years, during the Oedipal phase, and is derived from the relationship with both parents.

If the development of the child involves more than the "normal" traumatization (too difficult or too frequent experiences of a lack of empathic response, for example, or of divorce, disappointment and the like), the transformation of the two images (the self and the parent) will not occur; in such a situation they do not become integrated but continue to exist independently. If the grandiose self is traumatized in the midst of its development, the exhibitionistic narcissistic energy will not be able to reinvest itself in the grandiose self in modified form and the subject will ultimately be bereft of an adequate sense of self-esteem. If the idealizing narcissistic energy is traumatically disappointed in experiences with the idealized object it will revert to the idealized parent imago, thus depriving the subject's ideals of an adequate energy supply. Both images then retain psychic energy in repressed form or in a form that is separated from more realistic images; they will distort the development of the subject and prevent the later adult from acting and/or experiencing in a realistic way. The adult - each in his own way, of course, and to varying degrees - will remain tied to his (unconscious) delusions of grandeur and will act as if he were the center of the universe or will withdraw from everything because he is afraid that his extreme expectations will be disappointed. Or he will remain tied to the idealized parent imago and may spend his whole life looking for a parent substitute to which he can submit and with which he can identify, thereby sharing in the substitute's greatness but unable to stand on his own two feet. And if the expectations of such non-integrated self and object images are too badly disappointed, the adult may simply withdraw into the very early subrepresentatives of self and object. His self and his world will then fall apart and fragment and the person will go insane (Pietzcker 1983, pp. 45-46). Usually things do not go this far, however. In most cases such a psychic decompensation does not occur, and the narcissistically vulnerable person is still able to do an excellent job of presenting an image of himself to the outside world as adjusted and even successful, although often at great psychic expense. And here it should be noted once again that narcissism and its expressions need not be pathological as such. If transformed, the pole of the self known as the "grandiose self" will supply the energy that the I needs for its activities. And the idealizing narcissism, in its transformed form, will make possible such socially valued faculties as creativity, empathy, the ability to face one's own finiteness, humor and wisdom (Kohut 1966/1985, p. 111).

\section{Final words}

If we utilize a theory like Kohut's, we will be able to ask different questions, questions that may help us to interpret the story a particular person told us, questions that may enable us to help a patient. It is impossible to go further into practical consequences here. Let me finish by reiterating how important culture and context are for psychic functioning: in order to understand another person, we must pay attention to her context, we must know about the subcultural reality that has brought about the particular story we are confronted with. A religious story is the result of the person being embedded in a religious subculture, no single person invents a religion herself, in order to understand what another person is telling us religiously, we must be acquainted with the religious tradition she is speaking from. This stance requires great modesty from the individual counselor or psychotherapist: she should not think she could deal with all and each type of religion! She will often have to consult 
with experts on religious traditions unknown to herself, she will have to be careful not to remain stuck in stereotypes about religious traditions she may think to be acquainted with, she should perhaps transfer a patient to a colleague with a better knowledge of a religious tradition than she disposes of. Having drawn on a psychoanalytic theory that used the study of different types of transference as its main focus of empirical inquiry, I should perhaps express a last warning: even if a counselor is acquainted with the type of spirituality the patient is speaking from or relating to, this does not necessarily mean that the counselor is able to handle the issues of religion and/or spirituality well in the clinical context. All kinds of problems with countertransference may play a role, not in the least place the counselor's desire to work with the patient's religious self. In general, and perhaps contrary to what an increasing number of especially evangelical-Christian psychotherapists in the USA seem to think, it should be recommended not to do so: it comes close to instrumentalizing spirituality. For pastoral counselors doing so may an entry for action, but even they should realize how complicated the concept of the self, whether religious or not, is, as I hoped this paper has started to make aware of.

Open Access This article is distributed under the terms of the Creative Commons Attribution Noncommercial License which permits any noncommercial use, distribution, and reproduction in any medium, provided the original author(s) and source are credited.

\section{References}

Bakhtin, M. (1929). Problems of Dostoevsky's poetics. Ann Arbor: Ardis.

Belzen, J. A. (1999). Religion as embodiment: Cultural-psychological concepts and methods in the study of conversion among "Bevindelijken”. Journal for the Scientific Study of Religion, 38(2), 236-253.

Belzen, J. A. (2004). Religie, melancholie en zelf: Een historische en psychologische studie [Religion, melancholy and self: A historical and psychological study]. Kok: Kampen.

Bruner, J. (1990). Acts of meaning. Cambridge: Harvard University Press.

Freud, S. (1907). Zwangshandlungen und Religionsübungen. In A. Freud, et al. (Eds.), Gesammelte Werke: chronologisch geordnet. Band VII: Werke aus den Jahren 1906-1909 (pp. 129-139). London: Imago.

Guignon, C. (1998). Narrative explanation in psychotherapy. American Behavioral Scientist, 41, 558-577.

Haute, P. van (1993). Zijn en zelf [Being and self]. In J. M. Broekman, H. Feldmann \& P. van Haute (Eds.), Ziektebeelden [Images of illness] (pp. 151-179). Leuven: Peeters.

Heidegger, M. (1927). Sein und Zeit. Tübingen: Niemeyer.

Hermans, H. J. M., \& Kempen, H. J. G. (1993). The dialogical self: Meaning as movement. San Diego: Academic.

James, W. (1890). The principles of psychology. London: MacMillan.

James, W. (1902/2002). The varieties of religious experience: A study in human nature. London/New York: Routledge.

Kojève, A. (1947). Introduction à la lecture de Hegel: Leçons sur la phénoménologie de l'esprit. Paris: Gallimard.

Kohut, H. (1966/1985). Forms and transformations of narcissism. In Self psychology and the humanities: Reflections on a new psychoanalytic approach (pp. 97-123). New York: Norton.

Kohut, H. (1971). The analysis of the self: A systematic approach to the psychoanalytic treatment of narcissistic personality disorders. New York: International Universities Press.

Kohut, H. (1977). The restoration of the self. New York: International Universities Press.

Lacan, J. (1966). Écrits. [Writings] Paris: Seuil.

Lakoff, G., \& Johnson, M. (1980). Metaphors we live by. Chicago: University of Chicago Press.

McAdams, D. P. (2006). The redemptive self: Stories Americans live by. New York: Oxford University Press.

Mead, G. H. (1934). Mind, self, and society. Chicago: University of Chicago Press. 
Pietzcker, C. (1983). Einführung in die Psychoanalyse des literarischen Kunstwerks. Würzburg: Köninghausen \& Neumann.

Ratner, C. (2002). Cultural psychology: Theory and method. New York: Kluwer/Plenum.

Ricoeur, P. (1970). Freud and philosophy. New Haven: Yale University Press.

Ricoeur, P. (1981). Hermeneutics \& the human sciences. Cambridge: Cambridge University Press.

Rosenberg, S. D., Rosenberg, H. J., \& Farrell, M. P. (1992). In the name of the Father. In G. C. Rosenwald \& R. L. Ochberg (Eds.), Storied lives: The cultural politics of self-understanding (pp. 41-59). New Haven: Yale University Press.

Sarbin, T. R. (1986a). The narrative as a root metaphor for psychology. In T. R. Sarbin (Ed.), Narrative psychology: The storied nature of human conduct (pp. 3-21). New York: Praeger.

Sarbin, T. R. (1986b). Emotion and act: Roles and rhetoric. In R. Harré (Ed.), The social construction of emotions (pp. 83-97). Oxford: Blackwell.

Sarbin, T. R. (1993). The narrative as the root metaphor for contextualism. In S. C. Hayes, L. J. Hayes, H. W. Reese \& T. R. Sarbin (Eds.), Varieties of scientific contextualism (pp. 51-65). Reno: Context Press.

Sarbin, T. R., \& Scheibe, K. E. (Eds.). (1983). Studies in social identity. New York: Praeger.

Sarbin, T. R., \& Kitsuse, J. I. (Eds.). (1994). Constructing the social. London: Sage.

Spilka, B., Hood, R. W., Hunsberger, B., \& Gorsuch, R. L. (2003). The psychology of religion: An empirical approach (3rd ed.). New York: Guilford.

Sprinker, M. (1980). Fictions of the self: The end of autobiography. In J. Olney (Ed.), Autobiography: Essays theoretical and critical (pp. 321-342). Princeton: Princeton University Press.

Zwaal, P. van der (1997). De achtste vrije kunst: Psychoanalyse als retorica [The eighth liberal art: Psychoanalysis as rhetoric]. Meppel: Boom. 